\title{
METODE DEMONTRASI TERHADAP KETRAMPILAN PERAWATAN PAYUDARA PADA IBU HAMIL TRIMESTER III
}

\author{
Dina Wulandari ${ }^{1}$, Rindang Fitriana Ulfa ${ }^{2}$ \\ ${ }^{1}$ Universitas Kadiri Kediri \\ ${ }^{2}$ Akbid Harapan Mulya Ponorogo \\ Email : dinawulan@gmail.com,Rindang.fitrianaulfa1992@gmail.com
}

\begin{abstract}
Abstrak
Penelitian ini bertujuan untuk mengetahui Pengaruh Pemberian Metode Demonstrasi Terhadap Keterampilan Perawatan Payudara Pada Ibu Hamil Trimester III diKabupaten Kediri. Desain penelitian ini menggunakan pre-eksperimental. Populasi penelitian adalah seluruh ibu hamil Trimester III yang periksa di BPM "W" Kota Kediri. Jumlah sampel dalam penelitian ini adalah sejumlah 15 responden dengan cara menggunakan accidental sampling. Instrumen Penelitian ini menggunakan checklist perawatan payudara pada ibu hamil trimester III. Tekhnik analisa data menggunakan uji wilcoxon dengan signifikan 0,05.Dari hasil penelitian 15 responden pada keterampilan pasien hamil trimester III sebelum diberikan demonstrasi tentang perawatan payudara didapatkan hampir seluruhnya responden $(73,3 \%)$ tidak terampil melakukan perawatan payudara. Sesudah diberikan demonstrasi perawatan payudara didapatkan $80 \%$ ibu hamil trimester III terampil melakukan perawatan payudara. Yang dapat ditunjukkan dari hasil uji wilcoxon diperoleh $\mathrm{p}$ value : 0,002 pada $\alpha=0,05$. Karena $\mathrm{p}$ value $<\alpha$ maka $\mathrm{H} 0$ ditolak dan $\mathrm{H} 1$ diterima. Ada pengaruh pemberian metode demonstrasi terhadap keterampilan perawatan payudara pada ibu hamil trimester III di BPM "W"Kota Kediri
\end{abstract}

Kata Kunci : Demonstrasi, Perawatan Payudara, Ibu Hamil

\begin{abstract}
This study aims to determine the effect of the demonstration method on breast care skills in trimester III pregnant women in Kediri district. This research design uses pre-experimental. The study population was all Trimester III pregnant women who examined at BPM "W" Kediri City The number of samples in this study were 15 respondents in July 2015 by using accidental sampling. Instrument This study uses a breast care checklist in third trimester pregnant women. Data analysis techniques used Wilcoxon test with a significance of 0.05 . From the results of the study 15 respondents on the skills of third trimester pregnant patients before being given a demonstration about breast care found almost all respondents (73.3\%) were not skilled in breast care. After being given a demonstration of breast care, $80 \%$ of third trimester pregnant women are skilled in breast care. Which can be shown from the Wilcoxon test results obtained $\mathrm{p}$ value: 0.002 at $\alpha=0.05$. Because $\mathrm{p}$ value $<\alpha, \mathrm{H} 0$ is rejected and $\mathrm{H} 1$ is accepted.
\end{abstract}

Key words: Breast care, Pregnant women at third trimester, Demonstration 


\section{LATAR BELAKANG}

Dalam keluarga khususnya seorang ibu, kehamilan merupakan hal yang paling ditunggu - tunggu. Secara umum pada masa - masa kehamilan banyak mengalami perubahan fisik, alat reproduksi-nya, maupun psikologisnya. Seperti pada muka timbul kecoklatan, alat kandungan makin besar, payudara makin besar dan keras. Masalah yang terjadi apabila ibu hamil trimester III tidak melakukan perawatan payudara dan teknik perawatan payudara yang salah pada ibu hamil dapat menyebabkan terjadinya ASI tidak keluar, puting susu kadang tidak menonjol, produksi ASI sedikit, infeksi pada payudara, payudara bengkak, muncul benjolan di payudara, terjadi mastitis dan abses. Berdasarkan data Millenium Development Goal 4 ( MDGS4 ) angka kematian di Indonesia masih cukup tinggi yaitu sekitar 34/1000 kelahiran hidup, artinya 34 bayi meninggal pada setiap 1000 kelahiran. Dalam hal ini bangsa Indonesia harus mampu menurunkan angka kematian bayi menjadi 23/1000 kelahiran hidup pada tahun 2015 . ( Purwanti, 2010 )

Berdasarkan data Millenium Development Goal 4 ( MDGS4 ) angka kematian di Indonesia masih cukup tinggi yaitu sekitar 34/1000 kelahiran hidup, artinya 34 bayi meninggal pada setiap 1000 kelahiran. Dalam hal ini bangsa Indonesia harus mampu menurunkan angka kematian bayi menjadi 23/1000 kelahiran hidup pada tahun 2015 .

Hasil Survey Demografi Kesehatan Indonesia ( SDKI ) tahun 2010 menunjukkan bahwa ibu yang menyusui bayinya pada hari pertama setelah melahirkan yaitu sebesar 50,2 \%. Hal ini menunjukkan sekitar 49,8 \% ibu melahirkan tidak menyusui bayinya. Dari data tersebut sebanyak 63,6\% ibu melahirkan mengalami perlambatan pengeluaran ASI pada hari pertama. (Perinasia, 2010)

Menurut hasil penelitian sebelumnya oleh Andriani, 2006 di RSIA Siti Khadijah Makasar,menyatakan bahwa 86,7 \% pengeluaran ASI ibu post partum lancar setelah diberikan penjelasan dan demonstrasi tentang perawatan payudara selama hamil. Sebanyak 24,3 \% pengeluaran ASI ibu post partum tidak lancar karena kurangnya pengetahuan ibu tentang perawatan payudara.

Untuk mewujudkan terlaksananya perawatan payudara ibu hamil secara efektif diperlukan kerjasama keluarga dan petugas kesehatan serta kesaradan diri yang tinggi dari kader kesehatan dan ibu. Kemampuan ibu dalam melakukan perawatan payudara ibu hamil tidak dapat dipisahkan dari pengetahuan dan ketrampilan ibu tentang metode 
perawatan payudara. Peran bidan sebagai fasilitator dan motivator ibu dalam melakukan perawatan payudara pada ibu hamil harus meningkatkan pelayanan pendidikan kesehatan agar mampu mengajarkan tentang cara perawatan payudara pada ibu dan keluarga untuk memperlancar produksi ASI.

Berdasarkan hasil survey pendahuluan peneliti dalam wawancara dengan 20 orang ibu hamil trimester III di BPM "W" Kota Kediri, sebanyak 18 orang (80 \%) tidak bisa melakukan perawatan payudara dengan benar. Hal ini menunjukkan hanya 2 orang (20\%) ibu hamil yang dapat melakukan perawatan payudara secara benar.

\section{METODE PENELITIAN}

Desain penelitian yang digunakan dalam penelitian ini adalah dengan rancangan pre -eksperimental (One Group Pretest dan Posttest Design). Uji wilcoxon adalah suatu pengujian yang digunakan untuk mengetahui ada tidaknya perbedaan antara dua sampel dependen yang berpasangan atau berkaitan. Uji wilcoxon cocok digunakan apabila kita tidak hanya mengetahui besarnya setiap beda tetapi juga arah harga pengamatan yang bersangkutan, maka kita dapat menetapkan peringkat untuk masing-masing beda tersebut. Uji wilcoxon berfungsi untuk menguji perbedaan antar data berpasangan, menguji komparasi antar 2 pengamatan sebelum dan sesudah (before after design) dan mengetahui efektivitas suatu perlakuan. Populasi dalam penelitian ini adalah seluruh ibu hamil Trimester III yang periksa.Sampel penelitian adalah seluruh seluruh ibu hamil Trimester III yang periksa di BPM "W" Kota Kediri sebanyak 15 pasien.Teknik Pengambilan Sampel Dalam penelitian ini menggunakan teknik accidental sampling karena diambil dari sebagian populasi yang ditemui saat penelitian.

\section{HASIL DAN PEMBAHASAN}

Tabel 1 Frekuensi Keterampilan Pasien Hamil trimester III di BPM "W" Kota Kediri sebelum pemberian Demonstrasi Perawatan Payudara

\begin{tabular}{lll}
\hline Keterampilan & F & $(\%)$ \\
\hline Sangat Terampil & 2 & 13,3 \\
\hline Terampil & 2 & 13,3 \\
\hline Cukup terampil & 3 & 20 \\
\hline Tidak terampil & 8 & 53,3 \\
\hline
\end{tabular}




\begin{tabular}{ccc}
\hline Jumlah & 15 & 100 \\
\hline
\end{tabular}

Berdasarkan tabel 1 hasil penelitian dapat diketahui bahwasebelum penerapan metode demonstrasi perawatan payudara 15 responden sebagian besar $(53,3 \%)$ tidak terampil melakukan perawatan payudara. Dan 20\% (3 orang) cukup terampil merawat payudara. Sebanyak 13,3\% terampil dan 13,3\% sangat terampil dalam melakukan perawatan payudara.

Dari responden yang tidak terampil dalam merawat payudara, mayoritas tidak bekerja dan bekerja sebagai karyawan swasta. Responden yang tidak bekerja cenderung lebih pasif dalam menerima informasi karena kurangnya aktivitas sehingga menurunnya interaksi dengan individu lain. Kurangnya interaksi menyebabkan individu tersebut kurang mendapatkan informasi-informasi tentang kesehatan. Hal ini sesuai teori yang menyatakan bahwa lingkungan kerjaibu hamil akan mempengaruhi keterampilan perilaku kesehatan seseorang. Tingkat ekonomi yang baik memungkinkan individu memperoleh kebutuhan - kebutuhan yang lebih baik misalnya pendidikan, kesehatan pengembangan karier dan sebagainya. Demikian pula sebaliknya, jika individu tidak bekerja atau pendapatan lemah maka hal tersebut akan menghambat pemenuhan-pemenuhan kebutuhan tersebut. Kedaan ekonomi atau penghasilan memegang peranan penting dalam meningkatkan status kesehatan. Jenis pekerjaan seseorang erat kaitannya dengan tingkat penghasilan dan lingkungan kerja,( Zacler, 2009 )

Tabel 2 Frekuensi Keterampilan Ibu Hamil Trimester III di BPM "W" Kota Kediri setelah penerapan Metode Demonstrasi Perawatan Payudara

\begin{tabular}{lll}
\hline Keterampilan & F & $(\%)$ \\
\hline Sangat terampil & 3 & 20 \\
\hline Terampil & 9 & 60 \\
\hline Cukup terampil & 3 & 20 \\
\hline Tidak terampil & 0 & 0 \\
\hline Jumlah & 15 & 100 \\
\hline
\end{tabular}

Berdasarkan table 2 dapat diinterpretasikan bahwa setelah pemberian DemonstrasiPerawatan Payudara, Sebagian besar (60\%) dari responden memiliki 
kategori terampil dalam melakukan perawatan payudara. Ibu hamil yang cukup terampilini tinggal di daerah pedesaan dan mempunyai pendidikan terakhir SD. Hal ini sesuai dengan teori yang menyatakan bahwa motivasi belajar merupakan kekuatan mental yang mendorong terjadinya proses belajar. Motivasi belajar pada diri ibu hamil dapat menjadi lemah, apabila setiap hari diberikan mitos negatif tentang kehamilan dari keluarga yang tidak terlalu paham dengan dunia kesehatan. Selain motivasi, konsentrasi juga memegang peranan penting dalam keterampilan seseorang. Konsentrasi belajar merupakan kemampuan memusatkan perhatian pada proses demonstrasi perawatan payudara. Pemusatan perhatian tersebut tertuju pada isi bahan demonstrasimaupun proses memperolehnya. ( Sumiarsih, 2010)

Tabel 3 Tabulasi silang Pemberian Metode Demonstrasi Terhadap Keterampilan Perawatan Payudara Pada Ibu Hamil Trimester III di BPM "W” Kota Kediri

\begin{tabular}{|c|c|c|c|c|c|c|}
\hline \multirow[t]{3}{*}{ Ketrampilan } & \multicolumn{4}{|c|}{ Metode Demonstrasi } & \multirow{2}{*}{\multicolumn{2}{|c|}{ Total }} \\
\hline & \multicolumn{2}{|c|}{ Sebelum } & \multicolumn{2}{|c|}{ Sesudah } & & \\
\hline & $\mathrm{N}$ & $\%$ & $\mathrm{~N}$ & $\%$ & $\mathrm{~N}$ & $\%$ \\
\hline Sangat Teranpil & 2 & 13,3 & 3 & 20 & 5 & 16,7 \\
\hline Terampil & 2 & 13,3 & 9 & 60 & 11 & 36,7 \\
\hline Cukup Terampil & 3 & 20 & 3 & 20 & 6 & 20 \\
\hline Tidak Terampil & 8 & 53,3 & 0 & 0 & 8 & 26,6 \\
\hline Total & 15 & 100 & 15 & 100 & 30 & 100 \\
\hline $\mathrm{P}$ value $: 0,002$ & $\alpha: 0$, & & & & & \\
\hline
\end{tabular}

Berdasarkan tabel 3 dapat diinterpretasikan bahwa sebelum pemberian demonstrasi perawatan payudara, sebagian besar ibu hamil trimester III $(53,3 \%)$ menunjukkan ibu hamil tidak terampil dalam merawat payudara, sedangkan sesudah pemberian demonstrasi perawatan payudara, sebagian besar ibu hamil trimester III(60\%) menunjukkan bahwa ibu hamil terampil dalam merawat payudara.

Berdasarkan hasil uji statistik dengan menggunakan uji wilcoxon diperoleh nilai $p$ value : 0,002 pada $\alpha=0,05$. Karena $p$ value $<\alpha$ maka H0 ditolak dan H1 diterima. Artinya ada pengaruh Pemberian Metode Demonstrasi Terhadap Keterampilan Perawatan Payudara Pada Ibu Hamil Trimester III di BPM "W" Kota Kediri Tahun 2015 .

Metode demonstrasi dalam melakukan perawatan payudara pada ibu hamil dinilai lebih efektif karena responden mendapatkan suatu informasi tidak hanya dengan satu inderanamun menggunakan lebih dari satu inderanya, yaitu tahapan melihat melalui 
mata, tahapan mendengar melalui telinga dan sekaligus bisa langsung mempraktekkan terlebih dahulu. Selain itu demonstrasi ini berhasil karena umpan balik atau respon dari ibu hamil lebih banyak karena mereka diberikan demonstrasi secara privat, sehingga cenderung tidak malu bertanya dengan responden lain apabila tidak mengerti. ( Wayan, 2011 )

Faktor lain yang mendukung keberhasilan metode demonstrasi adalah jumlah responden yag diajar dalam satu ruangan merupakan aspek penting yang bisa mempengaruhi proses pembelajaran demonstrasi. Jumlah responden yang terlalu banyak akan kurang efektif untuk mencapai tujuan pembelajaran. Selain itu hubungan antara orang yang terlibat dalam lingkungan masyarakat juga sangat berpengaruh terhadap proses demonstrasi, misalnya iklim social antara ibu hamil dengan ibu hamil, antara ibu hamil dengan pendemonstrasi. Keharmonisan hubungan antara pihak tempat demonstrasi dengan dunia luar, misalnya hubungan bidan praktek tersebut dengan pamong desa untuk merangkul warganya agar memeriksakan kehamilannya, hubungan bidan praktek tersebut dengan lembaga-lembaga masyarakat, dan lain sebagainya. (Sumiarsih, 2010). Seperti penelitian yang dilakukan oleh ulfa farah lisa tahun 2018 dengan judul pengaruh demonstrasi terhadap ketrampilan perawatan payudara pada ibu hamil trimester ketiga didapatkan hasil ada pengaruh demonstrasi terhadap ketrampilan perawatan payudara pada ibu hamil trimester ketiga.

\section{KESIMPULAN DAN SARAN}

Ada pengaruh pemberian metode demonstrasi terhadap keterampilan perawatan payudara pada ibu hamil trimester III di BPM "W" Kota Kediri Tahun 2015. Saran Bagi Responden Diharapkan dengan penelitian ini, responden dapat menerapkan ilmu yang telah dipelajari untuk kedepannya Bagi Peneliti Selanjutnya Untuk peneliti selanjutnya, hendaknya mencoba metode kooperatif lainnya untuk membandingkan hasilnya dengan metode demonstrasi untuk memperoleh

\section{UCAPAN TERIMA KASIH}

Ucapan terima kasih kami ucapkan kepada responden yang bersedia menjadi sampel penelitian, bidan $\mathrm{W}$ yang sangat membantu pengumpulan data penelitian, serta pihak-pihak lain yang membantu dalam penyusunan penelitian ini 


\section{DAFTAR PUSTAKA}

Dharma, K.K., 2012, “ Metodologi penelitian keperawatan: Panduan melaksanakan dan menerapkan hasil penelitian. Jakarta : Trans Info Media.

Hegar,dkk, 2008. ASI adalah nutrisi alamiah terbaik bagi bayi dengan kandungan gizi paling sesuai untuk pertumbuhan optimal”, Jakarta : EGC

J.J. Hasibuan dan Mujiono. 2011 .’Proses Belajar Mengajar”. Bandung: PT. Remaja Rosdakarya.

P. Hadi, dkk, 2009 . "Melatihan paramedis tingkat nasional dalam peningkatan pemanfaatan ASI dan rawat gabung di rumah sakit”, Jakarta : perinasia.

Perinasia, 2010. "Program Managemen Laktasi", Jakarta : Bina Rupa Aksara,

S. Ruli, dkk,2010 . "Melindungi, meningkatan dan mendukung menyusui", Jakarta : EGC

S. Ruli, dkk,2011 . Menyusui dan rawat gabung, Jakarta, : perinasia.

Dahlan.(2010). Statistik untuk Kedokteran dan Kesehatan. Jakarta, Salemba Medika

Dewi, S. (2012). Asuhan Kehamilan Untuk Kebidanan. Jakarta, Salemba Medika

Fajar, Ibnu. (2010). Statistika Praktisi Kesehatan. Yogyakarta, Graha Ilmu

Ulfa, Farah Lisa (2018). Pengaruh Demonstrasi terhadap ketrampilan perawatan payudara pada ibu hamil trimester ketiga diwilayah kerja Puskesmas jeulingke kecamatan syiah kuala banda aceh Tahun 2018. Banda aceh, Universitas Ubudiyah Indonesia 